\title{
Efficacy of shockwave-enhanced Aloe vera gel on full-thickness wound healing: experimental study
}

\author{
DOI: https://doi.org/10.5114/pq.2020.92476
}

\author{
Hesham Galal Mahran \\ Department of Physical Therapy for Surgery, Faculty of Physical Therapy, Cairo University, Giza, Egypt
}

\begin{abstract}
Introduction. To investigate the efficacy of shockwave-enhanced Aloe vera gel on full-thickness wounds in rats.

Methods. Overall, 45 adult male rats were selected. Under anaesthesia, a skin area of $6 \mathrm{~cm} 2$ on the upper back of each animal was surgically excised. Then, the rats were divided by a randomization process into 3 groups. In group $A, 15$ rats received combined administration of topical Aloe vera gel with shockwave therapy $\left(600\right.$ shock pulses/session, 4 pulses $/$ second, at $0.1 \mathrm{~mJ} / \mathrm{mm}^{2}$ shock intensity). In group B, 15 rats received shockwave therapy with the same parameters as in group A, followed by topical application of Aloe vera gel for 150 seconds. In group C (control group), 15 rats received combined administration of topical Aloe vera gel with shockwave therapy while the device was switched off for 150 seconds. All groups received a total of 6 sessions: 2 sessions per week for 3 weeks. As outcome measures, wounded areas and shrinking rates were assessed at the third and sixth sessions in all groups.

Results. In the last session, there were significant wound contraction and shrinking rate measures in group A when compared with those in the other experimental group and in the control group.

Conclusions. Extracorporeal shockwave therapy may act as an efficient transdermal drug mediator as it maximized the healing effect of shockwave-combined Aloe vera gel on full-thickness wound healing.

Key words: rats, wound, extracorporeal shock wave, Aloe vera gel
\end{abstract}

\section{Introduction}

Shock wave is described as a series of high-energy biphasic sound pulses that spreads fast in 3 dimensions and produces temporary pressure changes. A sudden increase in pressure associated with a shock wave exerts a direct impact on the tissue without any side effects [1-3]. Shockwave therapy is commonly used to relieve chronic pain in sports injuries such as shoulder tendinitis, elbow epicondylitis, and calcareous spur [4-6]. Also, it has been applied for remedying chronic and acute injuries of the skin and soft tissue as it is considered a therapeutic healing tool [1-3].

Aloe vera plant is a member of the Aloeaceae family, represented by more than 400 species [7]. It includes different chemical compounds, such as polymannans, lectins, anthrone anthraquinone, C-glycosides, and acetylated mannans [8, 9]. Many Aloe vera components exert a healing effect, so the plant has several therapeutic applications. The thick, viscous gel of the Aloe vera leaf is included in different cosmetics and used in alternative medicine to heal wounds and other skin disorders [10]. The drug delivery process via the skin is a noninvasive and convenient method. It may be considered as an alternative to local injection in relieving pain. The introduction of therapeutic compounds via the skin with the use of ultrasound is known as sonophoresis [11].

It has been suggested that sonophoresis may enhance drug penetration into the skin, and this is mainly due to cavitation and thermal effects of ultrasound [12-14]. Shock wave as a transdermal drug mediator is considered a new modality, which has not been covered in research so far. Also, its mechanism in drug administration is not yet obvious and may be related, as suggested by some researchers [15-17], to the cavitation effect, which involves the production and movement of bubbles in a tissue, leading to mechanical and chemical changes [17, 18]. In this study, shock wave, as a transdermal drug mediator, was under investigation. The purpose was to assess the efficacy of Aloe vera gel enhanced by shock wave in rats with full-thickness wounds.

\section{Subjects and methods}

\section{Animals}

A total of 45 rats were selected from the house of animal of Faculty of Medicine at the Umm Al-Qura University. The animals met the following criteria: albino type, males, adults, age about 4 months, and weight range of 200-250 $\mathrm{g}$ at the start of the study. Each rat had its own stainless steel wire mesh cage. The room environment was controlled; the temperature was adjusted to $23-25^{\circ} \mathrm{C}$ and room humidity was $50 \%$. The food (Purina type with certificate number 5322) stored in the granular form was available with tap water for all animals throughout the duration of the study.

\section{Wound model preparation}

The skin area in the upper back of each rat was exposed to shaving, cleaning with alcohol (70\% concentration), and defining by stamp with $2 \times 3 \mathrm{~cm}$ dimensions. Then, under anaesthesia by inhalation of ethyl ether, surgical skin removal was the following step for producing full-thickness skin wound in the previously defined area of $6 \mathrm{~cm}^{2}$. All wound areas were surgically identified by one researcher.

Correspondence address: Hesham Galal Mahran, Department of Physical Therapy for Surgery, Faculty of Physical Therapy, Cairo University, 7 Ahmed ELzayat St. Bien Elsarayat, Dokky, Giza, Egypt, e-mail: heshammahran75@yahoo.com 


\section{Experiment design}

After the wound procedures, a randomization process was used in order to assign the rats into 3 groups: 2 experimental groups and 1 control group. So, the study was a randomized controlled study.

\section{Aloe vera gel amount}

The amount of Aloe vera gel used was determined in accordance with wound cavity dimensions as follows: each wound volume/cavity (length $\times$ width $\times$ depth) was approximately $1.2 \mathrm{~cm}^{3}\left(3 \times 2 \times 0.2 \mathrm{~cm}^{3}\right)$, so the amount of Aloe vera gel (comprised of Aloe vera with $87.399 \%$ concentration, manufactured by the Government Pharmaceutical Organization, Thailand) used to fill the wound size equalled approximately $1.2 \mathrm{~cm}^{3}$, with additional $0.3 \mathrm{~cm}^{3}$ to cover the wound edge. Thus, the total Aloe vera gel amount which was applied during the whole experiment in all groups was a $1.5 \mathrm{~cm}^{3}$ syringe.

\section{Treatment}

Within 2 hours after surgery, the wounds were cleaned with alcohol, and the treatment procedures began for all groups. In groups A and C, the wound cavity was filled with the measured amount of Aloe vera gel; during the first part of treatment (shockwave therapy) in group B, the wound cavity was filled with sonic gel. Then, shockwave therapy application started in all groups. A sterilized film/sheet made of plastic was used to cover each wound cavity to avoid device crosscontamination, followed by application of shockwave device (Duolith ${ }^{\circledR}$ SD1 T-Top, Storz Medical, Switzerland) with sonic gel over the wounded area and its boundaries, with movement through the plastic sheet for 150 seconds. With the exception of group B, after shockwave therapy, the second part of treatment (topical Aloe vera gel) was started by filling the wound cavity with the measured amount of Aloe vera gel for $150 \mathrm{sec}-$ onds. The treatment protocol in each group was as follows:

1. Experimental group $A: 15$ rats received combined administration of topical Aloe vera gel and shockwave therapy with the following parameters: 600 shock pulses, 4 pulses/ second, approximately 100 pulses $/ \mathrm{cm}^{2}, 0.1 \mathrm{~mJ} / \mathrm{mm}^{2}$ shock intensity [19-21], for 150 seconds.

2. Experimental group B: 15 rats received shockwave therapy (first part of treatment) with the same parameters as in group A, followed by topical application of Aloe vera gel (second part of treatment) for 150 seconds.

So, both experimental groups A and B were exposed to equal time of topical Aloe vera gel and shockwave therapy (150 seconds for each therapy) but group $B$ received sequential treatments while group A received combined treatment; therefore, any differences in outcome measures between the 2 groups would be related to shockwave-Aloe vera gel effect relationship.

3. Control group C: 15 rats received 150 seconds of combined administration of topical Aloe vera gel and shockwave therapy while the device was switched off to control the mechanical effect of shockwave transducer movement over the wound between groups.

In total, there were 6 sessions of treatment: 2 sessions per week for 3 weeks. At the end of each session, the wound areas were dried and cleaned with povidone solution.

\section{Measurements}

\section{Wound area contraction}

The mount of shrinkage in wound surface area was calculated with the tracing method as a transparent sterile film was placed on each wound for defining the wound boundary by using the tip of a fine marker. The area drawn on the film was copied on a graph paper; square millimetre numbers inside the drawn wounded area were counted and the total was converted to square centimetres and the area was recorded. For a valid measurement, each wounded area was measured 3 times and the mean of the 3 measures was calculated. The measuring procedure was repeated two times: after 3 and after 6 sessions.

\section{Wound shrinking rate}

The wound contraction rate at a session $(x)$ was estimated from the wound area $(\mathrm{A} 0)$ on day 0 and the unhealed area $(\mathrm{Ax})$ at the session $(\mathrm{x})$ by the following calculation:

$$
(A 0-A x / A 0) \times 100
$$

\section{Capturing images}

Images of each wound were captured by using a digital camera on day 0 and at the third and the sixth sessions of treatment in all groups.

\section{Statistical procedure}

After data collection, analysis was performed by using the SPSS software, version 16. Measure means as well as standard deviations were statistically estimated. Changes of measure means within each group throughout the phases of treatment were analysed with the repeated-measures ANOVA test, while changes of measure means between groups at each phase of treatment were evaluated with one-way ANOVA test. The level of significance was established at $p<0.05$.

\section{Ethical approval}

The research related to animal use has complied with all the relevant national regulations and institutional policies for the care and use of animals. The ethical standards of the Faculty of Medicine at the Umm Al-Qura University in Saudi Arabia were followed in applying all animal procedures. Also, all issues concerning the study aspects and protocol were approved by the ethics committee of the Faculty of Physical Therapy, Cairo University, Egypt.

\section{Results}

A comparison between different measures within each group elicited a significantly high shrinkage of the wounded areas throughout all measures $(p<0.05)$ (Table 1, Figures 1 and 2).

At the first session, the wounded area value was almost $6 \mathrm{~cm}^{2}$ in all groups and one-way ANOVA analysis revealed that the $p$-value between groups equalled 0.72 , so there were no significant differences between the groups. Additional analysis by post-hoc test confirmed the nonsignificant results between groups: A vs. B, B vs. C, A vs. C as the $p$-values were $0.51,0.9,0.47$, respectively.

Wounded areas mean values changed at the third session and equalled $2.12 \pm 0.34 \mathrm{~cm}^{2}$ with a $65.5 \pm 8.4 \%$ shrinking 
Table 1. Within-group and between-group comparisons of wounded areas mean values at 3 measuring points

\begin{tabular}{|c|c|c|c|c|c|c|c|c|}
\hline & \multicolumn{2}{|c|}{ Group A } & \multicolumn{2}{|c|}{ Group B } & \multicolumn{2}{|c|}{ Group C } & \multirow{2}{*}{$p$} & \multirow{2}{*}{ Post-hoc test } \\
\hline & WSA $\left(\mathrm{cm}^{2}\right)$ & Healing (\%) & WSA $\left(\mathrm{cm}^{2}\right)$ & Healing (\%) & WSA $\left(\mathrm{cm}^{2}\right)$ & Healing (\%) & & \\
\hline First session & $6.17 \pm 0.33$ & & $6.08 \pm 0.23$ & & $6.07 \pm 0.34$ & & 0.72 & $\begin{array}{l}0.51^{\mathrm{ab}} \\
0.9^{\mathrm{bc}} \\
0.47^{\mathrm{ac}}\end{array}$ \\
\hline Third session & $2.12 \pm 0.34$ & $65.5 \pm 8.4$ & $2.46 \pm 0.45$ & $59.5 \pm 6.3$ & $2.56 \pm 0.51$ & $57.8 \pm 7.3$ & 0.083 & $\begin{array}{l}0.096^{\mathrm{ab}} \\
0.61^{\mathrm{bc}} \\
0.034^{\mathrm{ac}}\end{array}$ \\
\hline Sixth session & $0.09 \pm 0.05$ & $98.5 \pm 0.6$ & $0.18 \pm 0.07$ & $97 \pm 0.45$ & $0.26 \pm 0.1$ & $95.7 \pm 0.4$ & 0.0001 & $\begin{array}{l}0.017^{\mathrm{ab}} \\
0.024^{\mathrm{bc}} \\
0.0001^{\mathrm{ac}}\end{array}$ \\
\hline$p$ & \multicolumn{2}{|c|}{0.0001} & \multicolumn{2}{|c|}{0.0001} & \multicolumn{2}{|c|}{0.0001} & & \\
\hline Repeated measures & \multicolumn{7}{|c|}{$0.0001^{1 \text { 1vs } 3}, 0.0001^{1 \mathrm{vs} 6}, 0.0001^{\text {3vs } 6}$ for all groups } & \\
\hline
\end{tabular}

WSA - wound surface area, $p^{\text {ab }}-$ group A vs. group B, $p^{\text {bc }}-$ group B vs. group C, $p^{\text {ac }}-$ group A vs. group C, $p^{1 v s 3}-1^{\text {st }}$ session vs. $3^{\text {rd }}$ session, $p^{\text {1vs } 6}-1^{\text {st }}$ session vs. $6^{\text {th }}$ session, $p^{3 v s 6}-3^{\text {rd }}$ session vs. $6^{\text {th }}$ session

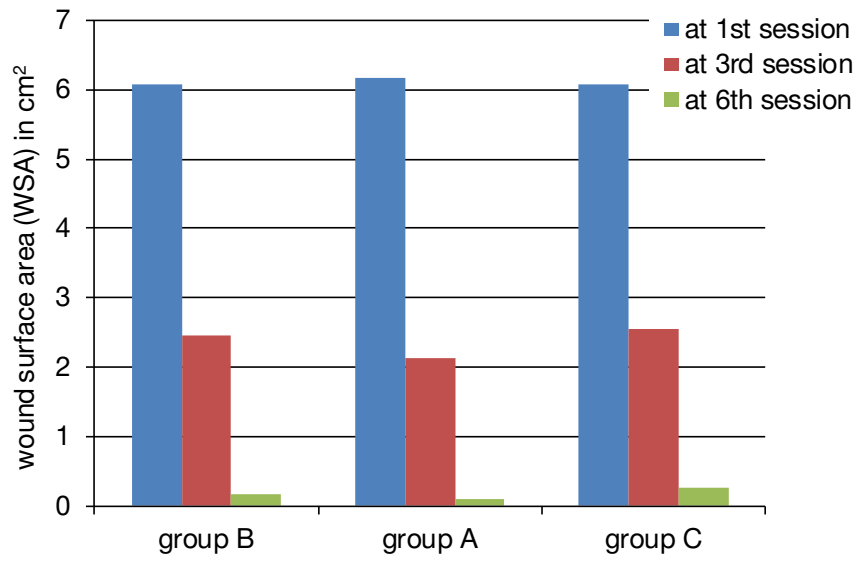

Figure 1. Within-group comparison of wounded areas mean values at 3 measuring points rate in group $A, 2.46 \pm 0.45 \mathrm{~cm}^{2}$ with a $59.5 \pm 6.3 \%$ shrinking rate in group $B$, and $2.56 \pm 0.51 \mathrm{~cm}^{2}$ with a $57.8 \pm 7.3 \%$ shrinking rate in group $\mathrm{C}$. One-way ANOVA analysis resulted in the $p$-value between groups of 0.083 , so there were no significant differences. Additional analysis by post-hoc test provided nonsignificant results between groups $A$ vs. $B$ and $B$ vs. C, with $p$-values of 0.096 and 0.61 , respectively, while a significant difference was observed between groups A vs. C, with $p$-value of 0.034 .

At the sixth session, the wounded areas mean values continued to change and equalled $0.09 \pm 0.05 \mathrm{~cm}^{2}$ with a $98.5 \pm$ $0.60 \%$ shrinking rate in group $A, 0.18 \pm 0.07 \mathrm{~cm}^{2}$ with a $97 \pm$ $0.45 \%$ shrinking rate in group $B$, and $0.26 \pm 0.1 \mathrm{~cm}^{2}$ with a $95.7 \pm 0.4 \%$ shrinking rate in group $C$. One-way ANOVA analysis resulted in the $p$-value between groups of 0.0001 , so there were highly significant differences. Post-hoc test confirmed the significant results between groups: A vs. B, B vs. C, $A$ vs. $C$ as the $p$-values were $0.017,0.024,0.0001$, respectively.

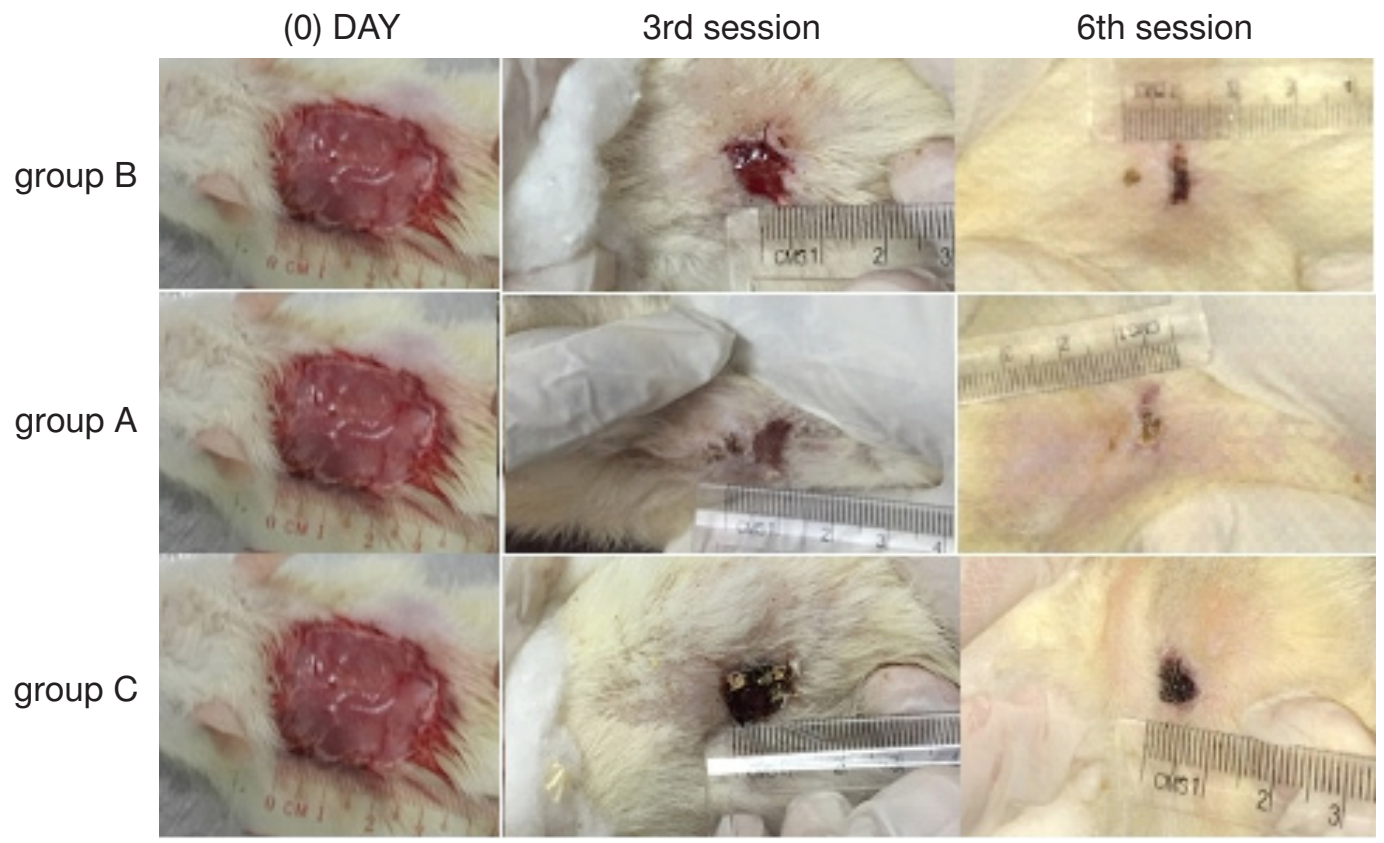

Figure 2. Wound images on day 0 and at the third and sixth sessions across groups 


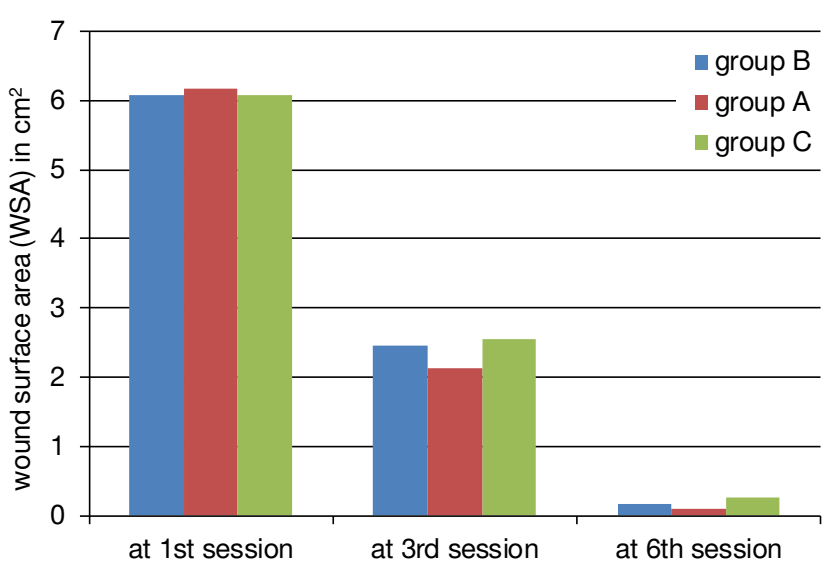

Figure 3. Between-group comparison of wounded areas mean values at 3 measuring points

Between-group results at the first, third, and sixth sessions are shown in Table 1 and Figures 2 and 3.

\section{Discussion}

In the presented study, a skin area in rats was excised to form a model of a wound in order to evaluate the efficacy of extracorporeal shockwave-enhanced transdermal Aloe vera gel in rat wound healing. The results of the study provide evidence that Aloe vera transdermal mediation via extracorporeal shock wave has a greater impact on wound healing, so the shock wave plays an important role in the transdermal administration of drugs with the full-thickness wound. Notably, the results within groups show that there was significant shrinking of wounded areas throughout all the 3 phases of measurements in all groups, with the $p$-value of 0.0001 . These results may be related to an enhanced healing effect of Aloe vera in all groups in addition to the positive effect of shock wave in both A and B groups. This remains consistent with several previous studies which confirmed the effect of Aloe vera as well as shock wave on wound healing, as described below.

\section{Aloe vera and wounds}

The healing properties of Aloe vera may be attributed to glucomannan, present richly in polysaccharides, such as mannose. Glucomannan stimulates the fibroblast growth factor, which positively affects fibroblast cell activity and its proliferation, and in turn enhances collagen production, improves the bonds in the helix, and speeds up wound healing [8]. Also, gene expression levels of vascular endothelial and transforming growth factors are elevated in the wound as an effect of Aloe vera. This leads to stimulating the fibroblasts and building up the extracellular matrix at the site of the wound [22].

Aloe vera treatment stimulated transforming growth factor TGF- $\beta 1$, which is an effective wound healing growth factor [23]. In human skin fibroblasts, mitosis is speeded up and increased by the action of TGF- $\beta 1$ [24]. Also, the angiogenesis process, myofibroblast differentiation, fibroblast formation, and extracellular matrix formation are stimulated by TGF [25].

Stimulation of macrophages in damaged tissues is attributed to the presence of Aloe vera mannose sugar. Also, macrophage cytokine production and cellular progression at certain wound healing stages after attachment to the recipient on the macrophage surface are stimulated by Aloe vera [26]. ent in Aloe vera, play a vital role in wound healing acceleration. Vitamin $\mathrm{C}$ enhances collagen production and increases healing tendency as a strong antioxidant [27]. Owing to its antimicrobial and anti-inflammatory effects, Aloe vera speeds up wound healing [2]. Antioxidant enzyme systems, such as superoxide dismutase and glutathione peroxidase, present in the mucosa of Aloe vera, accelerate healing through neutralizing the activity of free radicals on the wound and through their anti-inflammatory properties [28, 29].

\section{Shock wave and wounds}

In recent studies, shockwave therapy has been confirmed as a useful and efficient modality in wound healing because it stimulates some endogenous growth factors [30-33], enhances endothelial stem cell recruitment [34] and angiogenesis induction [35-37].

Extracorporeal shockwave therapy increases nitric oxide which is considered an effective vasodilator; hence, it has a positive effect on tissue perfusion. Also, shock waves enhance the induction of a powerful proangiogenic and vascular growth factor called vascular endothelial growth factor. In shockwave-treated tissues, overexpression for vascular endothelial growth factor has been detected [38].

In shockwave-treated tissues, inflammatory cytokines, chemokines suppression and multiple gene expressions of wound healing were found $[31,39]$. The shockwave anti-inflammatory effects have been confirmed in several studies concerning wounds $[30,40]$. Cell proliferation enhancement, extracellular matrix production, and apoptosis reduction are the actions of shockwave therapy in localized tissue lesions $[37,41]$. The comparison between groups at the third session revealed that the healing process in both groups $A$ and $B$ in the form of shrinking of wound surface was significantly more advanced than in group $\mathrm{C}$. This can be explained by the shockwave therapy effect on the healing process; this result is consistent with previous studies mentioned above.

At the sixth session, the results proved that group A presented better wound healing than groups $B$ and $C$ as there was a highly significant shrinkage in the wounded area and highly significant shrinking rate in group $A$ when compared with the wounded area and shrinking rate in the other groups. These results may be attributed to the maximum administration of Aloe vera gel by using shockwave therapy. In addition to its healing effect, shockwave therapy may enhance and maximize the effect of topical Aloe vera gel on fullthickness wound and this result may be consistent with the studies mentioned below.

\section{Shock wave as a transdermal mediator}

Drug delivery through the skin by using several methods has been investigated in research. Various energies have been applied to facilitate drug penetration through the skin. New technologies such as iontophoresis and phonophoresis are employed to ease the infiltration of drugs into stratum corneum, which is the transdermal penetration main barrier [42-44]. A pressure wave or shock wave can interrupt stratum corneum hydrophilic domains and promote the macromolecule release into the epidermis and the skin [45]. A transient increase in the permeability of cell membranes due to shock waves has been proved in vitro and in vivo. The mechanism of shock waves in increasing permeability may be related to the cavitation bubbles formation $[45,46]$.

Recent studies have shown that ultrasonic cavitation reduces the effectiveness of the skin barrier as a drug pene- 
tration insulator $[47,48]$. Cavitation leads to cell death and activates the transfer of large molecules into the cell. The cavitation energy is partially converted into different energy forms as shock waves form, or heat form, which can enhance diffusion by disrupting the biological tissues $[49,50]$. In vivo, shockwave therapy may be a useful method to increase tumour cell permeability and hence to introduce therapeutic molecules into these cells [46]. The effect of chemotherapy may be increased with shock waves; the method appears to be associated with a rise in intracellular drug concentration [49]. In addition, vaccine may be introduced in the same way through shock waves [51]. High amplitude and frequency of shock waves make the cavitation effect stronger than in many other forms of ultrasound therapy [52].

\section{Limitations}

The limitation of the study may be the number of rats in each group as an increased number may enforce the results.

\section{Conclusions}

Extracorporeal shockwave therapy may act as an efficient transdermal drug mediator as it maximized the healing effect of shockwave-combined Aloe vera gel on full-thickness wound healing.

\section{Disclosure statement}

The author does not have any financial interest and did not receive any financial benefit from this research.

\section{Conflict of interest}

The author states no conflict of interest.

\section{References}

1. Shrivastava SK, Kailash. Shock wave treatment in medicine. J Biosci. 2005;30(2):269-275; doi: 10.1007/BF02 703708.

2. Xin ZC, Liu J, Wang L, Li HX. Progress of low-energy shockwave therapy in clinical application [in Chinese]. Beijing Da Xue Xue Bao Yi Xue Ban. 2013;45(4):657-660.

3. Qureshi AA, Ross KM, Ogawa R, Orgill DP. Shock wave therapy in wound healing. Plast Reconstr Surg. 2011; 128(6):721e-727e; doi:10.1097/PRS.0b013e318230c7d1.

4. Pleiner J, Crevenna R, Langenberger $H$, Keilani $M$, Nuhr M, Kainberger F, et al. Extracorporeal shockwave treatment is effective in calcific tendonitis of the shoulder. A randomized controlled trial. Wien Klin Wochenschr. 2004;116(15-16):536-541; doi: 10.1007/BF03217707.

5. Rompe JD, Riedel C, Betz U, Fink C. Chronic lateral epicondylitis of the elbow: a prospective study of low-energy shockwave therapy and low-energy shockwave therapy plus manual therapy of the cervical spine. Arch Phys Med Rehabil. 2001;82(5):578-582; doi: 10.1053/apmr.2001. 22337.

6. Wang CJ, Chen HS, Huang TW. Shockwave therapy for patients with plantar fasciitis: a one-year follow-up study. Foot Ankle Int. 2002;23(3):204-207; doi: 10.1177/107 110070202300303.

7. Sánchez-Machado DI, López-Cervantes J, Sendón R, Sanches-Silva A. Aloe vera: ancient knowledge with new frontiers. Trends Food Sci Tech. 2017;61:94-102; doi: 10.1016/j.tifs.2016.12.005

8. Boudreau MD, Beland FA. An evaluation of the biological and toxicological properties of Aloe barbadensis (Miller), Aloe vera. J Environ Sci Health C Environ Carcinog Eco- toxicol Rev. 2006;24(1):103-154; doi: 10.1080/10590 500600614303.

9. Eshun K, He Q. Aloe vera: a valuable ingredient for the food, pharmaceutical and cosmetic industries - a review. Crit Rev Food Sci Nutr. 2004;44(2):91-96; doi: 10.1080/ 10408690490424694.

10. Surjushe A, Vasani R, Saple DG. Aloe vera: a short review. Indian J Dermatol. 2008;53(4):163-166; doi: 10.4103/ 0019-5154.44785.

11. Escobar-Chávez JJ, Bonilla-Martínez D, Villegas-González MA, Rodríguez-Cruz IM, Domínguez-Delgado CL. The use of sonophoresis in the administration of drugs throughout the skin. J Pharm Pharm Sci. 2009;12(1):88115; doi: 10.18433/J3C30D.

12. Hippius M, Uhlemann C, Smolenski U, Schreiber U, Reissig S, Hoffmann A. In vitro investigations of drug release and penetration - enhancing effect of ultrasound on transmembrane transport of flufenamic acid. Int $\mathrm{J}$ Clin Pharmacol Ther. 1998;36(2):107-111.

13. Singer AJ, Homan CS, Church AL, McClain SA. Low-frequency sonophoresis: pathologic and thermal effects in dogs. Acad Emerg Med. 1998;5(1):35-40; doi: 10.1111/ j.1553-2712.1998.tb02572.x.

14. Ueda H, Mutoh M, Seki T, Kobayashi D, Morimoto Y. Acoustic cavitation as an enhancing mechanism of lowfrequency sonophoresis for transdermal drug delivery. Biol Pharm Bull. 2009;32(5):916-920; doi: 10.1248/ bpb.32.916.

15. Alkhamaali ZK, Crocombe AD, Solan MC, Cirovic S. Finite element modelling of radial shock wave therapy for chronic plantar fasciitis. Comput Methods Biomech Biomed Engin. 2016;19(10):1069-1078; doi: 10.1080/ 10255842.2015.1096348.

16. Chow IH, Cheing GL. Comparison of different energy densities of extracorporeal shock wave therapy (ESWT) for the management of chronic heel pain. Clin Rehabil. 2007;21(2):131-141; doi:10.1177/0269215506069244.

17. Delius M, Draenert K, Al Diek Y, Draenert Y. Biological effects of shock waves: in vivo effect of high energy pulses on rabbit bone. Ultrasound Med Biol. 1995;21(9): 1219-1225; doi: 10.1016/0301-5629(95)00030-5.

18. Munver R, Delvecchio FC, Kuo RL, Brown SA, Zhong P, Preminger GM. In vivo assessment of free radical activity during shock wave lithotripsy using a microdialysis system: the renoprotective action of allopurinol. J Urol. 2002; 167(1):327-334; doi: 10.1016/S0022-5347(05)65463-8.

19. Yang G, Luo C, Yan X, Cheng L, Chai Y. Extracorporeal shock wave treatment improves incisional wound healing in diabetic rats. Tohoku J Exp Med. 2011;225(4):285292; doi: 10.1620/tjem.225.285.

20. Djedovic G, Kamelger FS, Jeschke J, Piza-Katzer H. Effect of extracorporeal shock wave treatment on deep partial-thickness burn injury in rats: a pilot study. Plast Surg Int. 2014;2014:495967; doi:10.1155/2014/495967.

21. Mahran HG. Dose dependent effect of shock wave therapy on full-thickness wound healing: an experimental study. Arch Clin Exp Surg. 2016;5(1):33-41; doi: 10.5455/ aces.20150624022549.

22. Atiba A, Ueno H, Uzuka Y. The effect of Aloe vera oral administration on cutaneous wound healing in type 2 diabetic rats. J Vet Med Sci. 2011;73(5):583-589; doi: 10.1292/jvms.10-0438.

23. Shi $Y$, Massagué J. Mechanisms of TGF- $\beta$ signaling from cell membrane to the nucleus. Cell. 2003;113(6):685700; doi: 10.1016/S0092-8674(03)00432-X. 
24. Massagué J. The transforming growth factor-beta family. Annu Rev Cell Biol. 1990;6:597-641; doi: 10.1146/annurev.cb.06.110190.003121.

25. Sánchez-Elsner T, Botella LM, Velasco B, Corbí A, Attisano L, Bernabéu C. Synergistic cooperation between hypoxia and transforming growth factor- $\beta$ pathways on human vascular endothelial growth factor gene expression. J Biol Chem. 2001;276(42):38527-38535; doi: 10.1074/jbc.M104536200.

26. Liu C, Leung MY, Koon JC, Zhu LF, Hui YZ, Yu B, et al. Macrophage activation by polysaccharide biological response modifier isolated from Aloe vera $\mathrm{L}$. var. chinensis (Haw.) Berg. Int Immunopharmacol. 2006;6(11):16341641; doi: 10.1016/j.intimp.2006.04.013.

27. Kashanian M, Lakeh MM, Ghasemi A, Noori S. Evaluation of the effect of vitamin $E$ on pelvic pain reduction in women suffering from primary dysmenorrhea. J Reprod Med. 2013;58(1-2):34-38.

28. Somboonwong J, Thanamittramanee S, Jariyapongskul A, Patumraj S. Therapeutic effects of Aloe vera on cutaneous microcirculation and wound healing in second degree burn model in rats. J Med Assoc Thai. 2000;83(4): 417-425.

29. Hajhashemi V, Ghannadi A, Heidari AH. Anti-inflammatory and wound healing activities of Aloe littoralis in rats. Res Pharm Sci. 2012;7(2):73-78.

30. Davis TA, Stojadinovic A, Anam K, Amare M, Naik S, Peoples GE, et al. Extracorporeal shock wave therapy suppresses the early pro-inflammatory immune response to a severe cutaneous burn injury. Int Wound J. 2009; 6(1):11-21; doi: 10.1111/j.1742-481X.2008.00540.x.

31. Zins SR, Amare MF, Tadaki DK, Elster EA, Davis TA. Comparative analysis of angiogenic gene expression in normal and impaired wound healing in diabetic mice: effects of extracorporeal shock wave therapy. Angiogenesis. 2010;13(4):293-304; doi: 10.1007/s10456-0109186-9.

32. Bosch $G$, de Mos M, van Binsbergen R, van Schie HT, van de Lest $\mathrm{CH}$, van Weeren PR. The effect of focused extracorporeal shock wave therapy on collagen matrix and gene expression in normal tendons and ligaments. Equine Vet J. 2009;41(4):335-341; doi: 10.2746/0425 16409X370766.

33. Martini L, Giavaresi G, Fini M, Torricelli P, de Pretto M, Schaden W, et al. Effect of extracorporeal shock wave therapy on osteoblastlike cells. Clin Orthop Relat Res. 2003;413:269-280; doi: 10.1097/01.blo.0000073344.50 837.cd.

34. Aicher A, Heeschen C, Sasaki K, Urbich C, Zeiher AM, Dimmeler S. Low-energy shock wave for enhancing recruitment of endothelial progenitor cells: a new modality to increase efficacy of cell therapy in chronic hind limb ischemia. Circulation. 2006;114(25):2823-2830; doi: 10.1161/CIRCULATIONAHA.106.628623.

35. Zimpfer D, Aharinejad S, Holfeld J, Thomas A, Dumfarth J, Rosenhek R, et al. Direct epicardial shock wave therapy improves ventricular function and induces angiogenesis in ischemic heart failure. J Thorac Cardiovasc Surg. 2009;137(4):963-970; doi: 10.1016/j.jtcvs.2008. 11.006.

36. Sobczak M, Kasprzak JD. Cardiac shock wave therapy - a new method for treatment of advanced coronary disease and refractory angina [in Polish]. Kardiol Pol. 2010; 68(12):1391-1396.

37. Yip HK, Chang LT, Sun CK, Youssef AA, Sheu JJ, row-derived mononuclear cells enhances formation of cells stained positive for CD31 and vascular endothelial growth factor. Circ J. 2008;72(1):150-156; doi: 10.1253/ circj.72.150.

38. Ma HZ, Zeng BF, Li XL. Upregulation of VEGF in subchondral bone of necrotic femoral heads in rabbits with use of extracorporeal shock waves. Calcif Tissue Int. 2007;81(2):124-131; doi: 10.1007/s00223-007-9046-9.

39. Stojadinovic A, Elster EA, Anam K, Tadaki D, Amare M, Zins S, et al. Angiogenic response to extracorporeal shock wave treatment in murine skin isografts. Angiogenesis. 2008;11(4):369-380; doi: 10.1007/s10456008-9120-6.

40. Kuo YR, Wang CT, Wang FS, Yang KD, Chiang YC, Wang CJ. Extracorporeal shock wave treatment modulates skin fibroblast recruitment and leukocyte infiltration for enhancing extended skin-flap survival. Wound Repair Regen.2009;17(1):80-87;doi:10.1111/j.1524-475X.2008. 00444.x.

41. Chao YH, Tsuang YH, Sun JS, Chen LT, Chiang YF, Wang CC, et al. Effects of shock waves on tenocyte proliferation and extracellular matrix metabolism. Ultrasound Med Biol. 2008;34(5):841-852; doi: 10.1016/j. ultrasmedbio.2007.11.002.

42. Kassan DG, Lynch AM, Stiller MJ. Physical enhancement of dermatologic drug delivery: iontophoresis and phonophoresis. J Am Acad Dermatol. 1996;34(4):657666; doi: 10.1016/s0190-9622(96)80069-7.

43. Menon GK, Kollias N, Doukas AG. Ultrastructural evidence of stratum corneum permeabilization induced by photomechanical waves. J Invest Dermatol. 2003;121(1): 104-109; doi: 10.1046/j.1523-1747.2003.12302.x.

44. Prausnitz MR, Langer R. Transdermal drug delivery. Nat Biotechnol. 2008;26(11):1261-1268; doi: 10.1038/nbt. 1504.

45. Doukas AG, Kollias N. Transdermal drug delivery with a pressure wave. Adv Drug Deliv Rev. 2004;56(5):559579; doi: 10.1016/j.addr.2003.10.031.

46. Gambihler S, Delius M. In vitro interaction of lithotripter shock waves and cytotoxic drugs. Br J Cancer. 1992; 66(1):69-73; doi: 10.1038/bjc.1992.218.

47. Machet L, Boucaud A. Phonophoresis: efficiency, mechanisms and skin tolerance. Int J Pharm. 2002;243(1-2): 1-15; doi: 10.1016/S0378-5173(02)00299-5.

48. Rao R, Nanda S. Sonophoresis: recent advancements and future trends. J Pharm Pharmacol. 2009;61(6):689705; doi: 10.1211/jpp.61.06.0001.

49. Delius M, Adams G. Shock wave permeabilization with ribosome inactivating proteins: a new approach to tumor therapy. Cancer Res. 1999;59(20):5227-5232.

50. Kodama T, Doukas AG, Hamblin MR. Shock wave-mediated molecular delivery into cells. Biochim Biophys Acta. 2002;1542(1-3):186-194; doi: 10.1016/s0167-4889 (01)00177-x.

51. Jagadeesh G, Prakash GD, Rakesh SG, Allam US, Krishna MG, Eswarappa SM, et al. Needleless vaccine delivery using micro-shock waves. Clin Vaccine Immunol. 2011; 18(4):539-545; doi: 10.1128/CVI.00494-10.

52. Meaney PM, Cahill MD, ter Haar GR. The intensity dependence of lesion position shift during focused ultrasound surgery. Ultrasound Med Biol. 2000;26(3):441-450; doi: 10.1016/S0301-5629(99)00161-1. 